\title{
ANALISIS PEMBERIAN REWARD PADA SISTEM INFORMASI MANAJEMEN KEPEGAWAIAN DI PT. SWAMEDIA INFORMATIKA
}

\author{
Anna Dara Andriana, Rani Susanto \\ Universitas Komputer Indonesia \\ e-mail: anna.dara.andriana@email.unikom.ac.id
}

\begin{abstract}
The Purpose of Human Resource Management Information System is to ensure that companies can achieve strategic objectives with all as human resources that can be relied upon to meet the needs of companies with good quality. The Human Resources Management Information System consists of several modules that are interrelated to produce information to support the results of human resource management in the company. Rewards to Employees is one of the modules of the Human Resources Management Information System that is important because rewards are a form of appreciation from the company to employees with the hope as motivation for employees to excel in achieving company goals. The problem that occurs in this company is when determining which employees are entitled to receive rewards. The current assessment still does not pay attention to the level of importance in each of the assessment criteria so that frequent valuation errors and rewards are given to employees. Therefore, giving rewards to employees must be done well and can be accounted for. Analytical Hierarchy Process method or called AHP is used to assist in the determination of employees who are entitled to receive rewards. AHP method is a method for solving a complex situation that is not structured into a component and hierarchy arrangement by providing subjective values and determining which variable has the highest priority. This method can provide recommendations for rewarding employees based on the highest value as the best value.
\end{abstract}

Key words: Human Resource Management Information System, Analytical Hierarchy Process, Reward

\section{ABSTRAK}

Sistem Informasi Manajemen Kepegawaian atau SIM Kepegawaian bertujuan untuk memastikan agar perusahaan dapat mencapai tujuan strategisnya dengan memiliki karyawan selaku sumber daya manusia yang dapat diandalkan untuk memenuhi kebutuhan perusahaan baik secara kualitas maupun kuantitas. SIM Kepegawaian terdiri dari beberapa modul yang saling terintegrasi untuk menghasilkan informasi yang bermutu untuk menunjang keputusan manajemen kepegegawaian di perusahaan. Pemberian Reward kepada Karyawan merupakan salah satu modul dari SIM Kepegawaian yang penting karena reward merupakan bentuk apresiasi dari perusahaan kepada karyawan dengan harapan sebagai motivasi bagi karyawan untuk berprestasi dalam mencapai tujuan perusahaan. Masalah yang terjadi di perusahaan ini yaitu pada saat penentuan karyawan yang berhak mendapatkan reward. Penilaian yang sekarang dilakukan masih belum memperhatikan tingkat kepentingan di setiap kriteria penilaian sehingga sering terjadinya kesalahan penilaian dan pemberian reward kepada karyawan. Oleh karena itu, pemberian reward kepada karyawan harus dilakukan dengan baik dan dapat dipertanggungjawabkan. Metode Analytical Hierarchy Process atau disebut dengan AHP digunakan untuk membantu dalam kegiatan penentuan karyawan yang berhak mendapatkan reward. Metode AHP merupakan metode untuk memecahkan suatu situasi yang kompleks yang tidak terstruktur kedalam suatu komponen dan susunan hierarki dengan memberikan nilai subjektif dan menetapkan variable mana yang memiliki prioritas paling tinggi. Metode ini dapat memberikan rekomendasi pemberian reward kepada karyawan berdasarkan nilai paling tinggi sebagai nilai terbaik.

Kata Kunci: Sistem Informasi Manajemen Kepegawaian, Analytical Hierarchy Process, Reward 


\section{PENDAHULUAN}

Sistem Informasi Manajemen Kepegawaian atau SIM Kepegawaian bertujuan untuk memastikan agar perusahaan dapat mencapai tujuan strategisnya dengan memiliki karyawan selaku sumber daya manusia yang dapat diandalkan untuk memenuhi kebutuhan perusahaan baik secara kualitas maupun kuantitas [1]. SIM Kepegawaian terdiri dari beberapa modul yang saling terintegrasi untuk menghasilkan informasi yang bermutu untuk menunjang keputusan manajemen kepegegawaian di perusahaan yang dimulai dari proses perekrutan dan penerimaan karyawan (recruiting and hiring), penilaian kinerja karyawan, pemberian reward serta prosedur manajemen kepegawaian yang lain seperti cuti, pensiun hingga pelatihan karyawan [2].

Pemberian reward kepada Karyawan merupakan salah satu modul dari sistem informasi manajemen Kepegawaian yang penting karena reward merupakan bentuk apresiasi dari perusahaan kepada karyawan dengan harapan sebagai motivasi bagi karyawan untuk berprestasi dalam mencapai tujuan-tujuan perusahaan.

PT. SWAMEDIA INFORMATIKA adalah perusahaan yang memiliki 150 orang karyawan dan terdiri dari 2 cabang. Perusahaan ini bergerak dibidang pengembangan dan pembuatan perangkat lunak. Pemberian reward pada perusahaan dianggap sangat penting, karena intensitas kerja yang tinggi, sehingga perusahaan didorong untuk dapat menjaga dan meningkatkan motivasi setiap karyawan,agar setiap pekerjaan dapat diselesaikan dengan baik dan sesuai target, salah satunya dengan memberikan reward.

Masalah yang terjadi di perusahaan ini yaitu pada saat penentuan karyawan yang berhak mendapatkan reward. Kegiatan penilaian yang sekarang dilakukan masih belum memperhatikan tingkat kepentingan di setiap kriteria penilaian sehingga sering terjadinya kesalahan penilaian dan pemberian reward kepada karyawan. Karyawan yang seharusnya tidak berhak mendapatkan reward, tetapi mendapatkannya sedangkan yang seharusnya mendapatkan tetapi tidak mendapatkannya. Hal ini mengakibatkan motivasi dan kinerja karyawan yang menurun dikarenakan adanya kesenjangan dan kesalahan penilaian karyawan dalam pemberian reward.

Metode Analytical Hierarchy Process atau disebut dengan AHP digunakan untuk membantu dalam kegiatan penentuan karyawan yang berhak mendapatkan reward. Metode AHP merupakan metode untuk memecahkan suatu situasi yang kompleks yang tidak terstruktur kedalam suatu komponen dan susunan hierarki dengan memberikan nilai subjektif dan menetapkan variabel mana yang mem- iliki prioritas paling tinggi [3]. Metode ini dapat memberikan rekomendasi pemberian reward kepada karyawan berdasarkan nilai paling tinggi sebagai nilai terbaik.

Tujuan dari penelitian ini adalah untuk membantu dalam memberikan rekomendasi pemberian reward kepada karyawan agar motivasi dan kinerja karyawan tetap terjaga dengan baik.

\section{INJAUAN PUSTAKA}

\section{Sistem Informasi Manajemen Kepegawaian}

Sistem Informasi Manajemen atau SIM merupakan sistem berdasarkan komputer yang menjadikan informasi dapat digunakan oleh para manajer untuk kebutuhan yang sama. Ada tiga pengertian Sumber daya manusia yaitu:

a. Sumber daya manusia adalah manusia yang bekerja dilingkungan suatu organisasi (disebut juga personil, tenaga kerja, pekerja atau karyawan).

b. Sumber daya manusia adalah potensi manusiawi sebagai penggerak organisasi dalam mewujudkan eksistensinya. [4]

Sistem informasi Kepegawaian (human resouces information system) adalah prosedur sistematik untuk pengumpulan, menyimpan, mempertahankan, menarik dan memvalidasi data yang dibutuhkan oleh sebuah perusahaan untuk meningkatkan keputusan sumber daya manusia. [5]

\section{Analisis PDCA}

PDCA, singkatan dari Plan-Do-Check-Action adalah suatu proses pengendalian kualitas yang diperkenalkan oleh Dr. W. Edwards Deming yang cocok digunakan untuk dipergunakan pada skala kecil kegiatan continuous improvement yang bertujuan untuk memperpendek siklus kerja, serta pemborosan produktifitas di perusahaan [6]. Siklus PDCA terlihat pada Gambar 1.

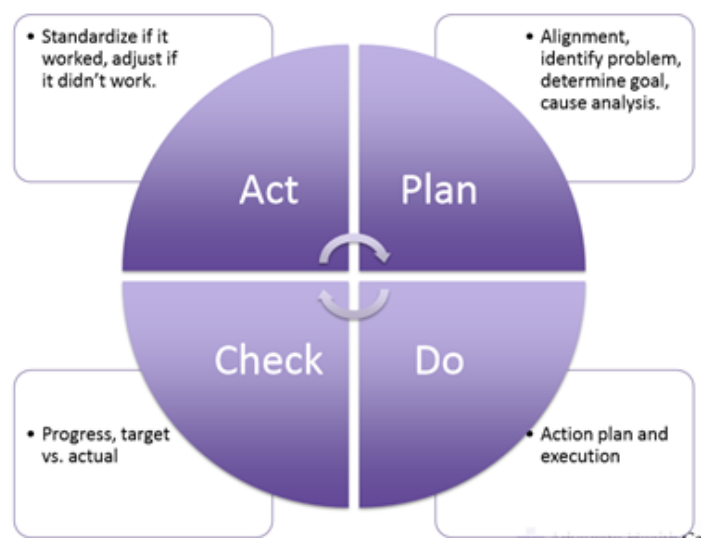

Gambar 1. Siklus PDCA [7] 
a. Plan (Rencanakan): identifikasi masalah, menentukan tujuan yang ingin dicapai dan menganalisa penyebab masalah.

b. Do (Kerjakan): mengeksekusi apa yang ada di tahap plan.

c. Check (Cek): hasil pemantauan dan evaluasi yang sudah dilakukan, apakah sesuai dengan yang direncanakan pada tahap plan.

d. Act (Tindak lanjuti): menindaklanjuti hasil untuk membuat perbaikan yang diperlukan.

\section{Metode Analytical Hierarchy Process (AHP)}

Metode AHP merupakan metode untuk memecahkan suatu situasi yang kompleks yang tidak terstruktur kedalam suatu komponen dan susunan hierarki dengan memberikan nilai subjektif dan menetapkan variabel mana yang memiliki prioritas paling tinggi [3].

AHP sering digunakan sebagai metode pemecahan masalah dibanding dengan metode yang lain karena alasan-alasan sebagai berikut :

a. Struktur yang berhirarki, sebagai konsekuesi dari kriteria yang dipilih, sampai pada subkriteria yang paling dalam.

b. Memperhitungkan validitas sampai dengan batas toleransi inkonsistensi berbagai kriteria dan alternatif yang dipilih oleh pengambil keputusan

c. Memperhitungkan daya tahan output analisis sensitivitas pengambilan keputusan

\section{METODE}

Pendekatan kuantitatif dengan menggunakan metode deskriptif, yaitu melakukan studi komparatif untuk membandingkan fenomena yang ditemukan dan membuat klasifikasi yang bersumber pada suatu standar merupakan pendekatan yang digunakan pada penelitian ini. Langkah-langkah penelitian yang telah dilakukan pada penelitian ini terlihat pada Gambar 2.

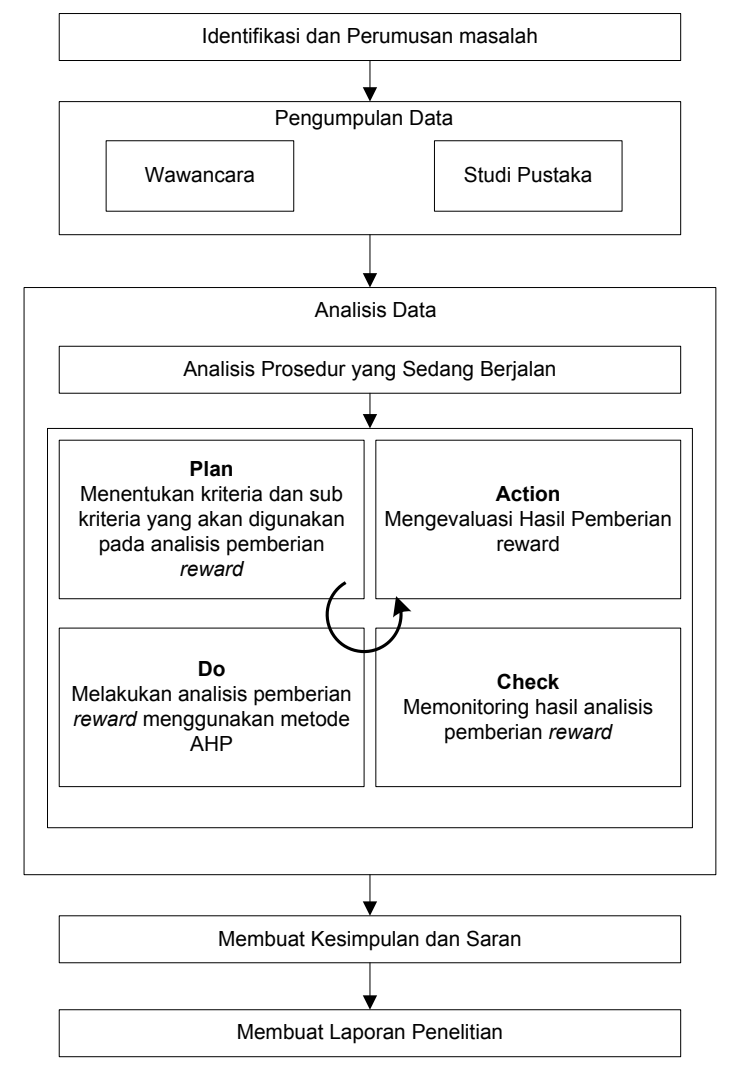

Gambar 2. Langkah Penelitian

\section{HASIL DAN PEMBAHASAN}

\section{Analisis Masalah}

Masalah yang dihadapi oleh perusahaan ini yaitu ketika menentukan pegawai yang akan mendapatkan reward karena dalam penilaian yang sedang berjalan belum melihat tingkat kepentingan di setiap kriteria maupun sub kriteria.

\section{Analisis Sistem yang Berjalan}

Alur kegiatan pemilihan karyawan yang akan mendapatkan reward terlihat pada Gambar 3. 


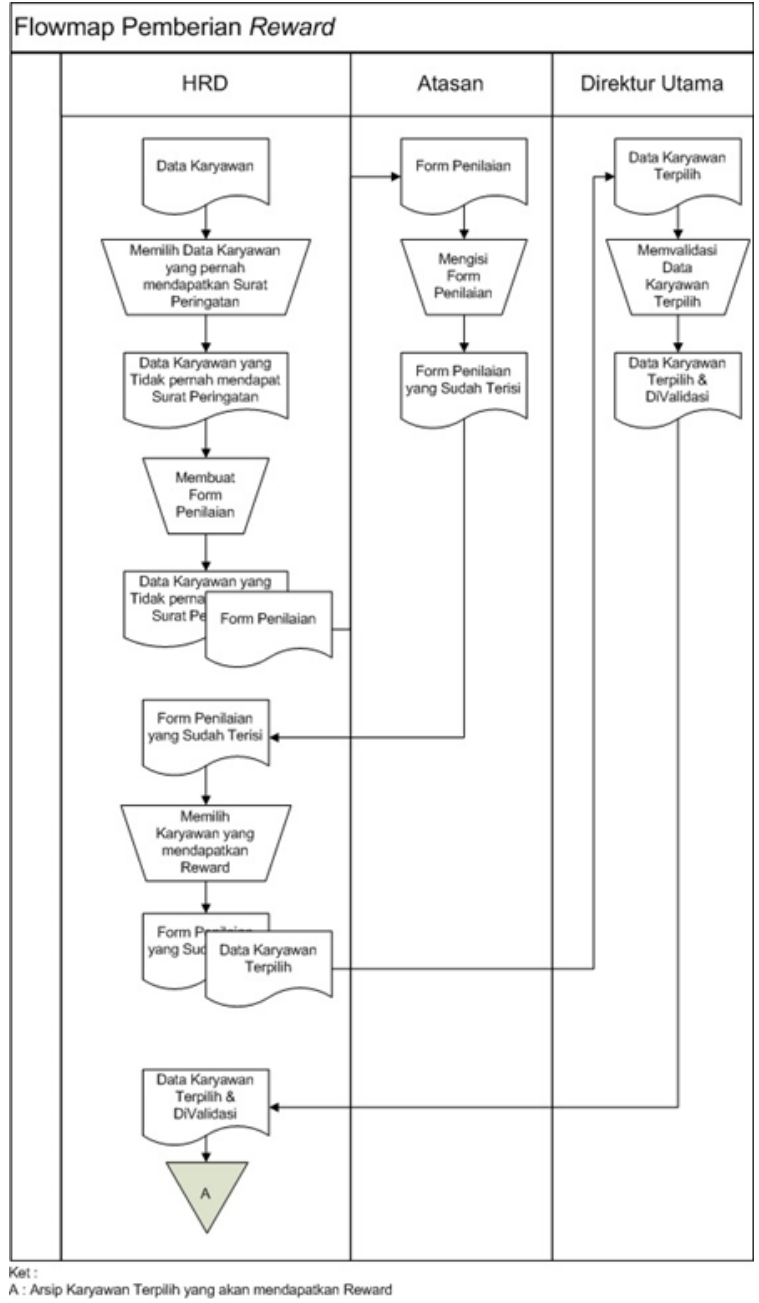

Gambar 3. Flowmap Pemberian Reward

\section{Analisis PDCA Pemberian Reward}

Analisis PDCA (Plan, Do, Check, Act ) ini akan digunakan untuk memodelkan sistem yang akan dibangun selanjutnya sebagai kelanjutan dari penelitian ini nantinya. Model PDCA akan dibangun dan dibatasi hanya untuk proses pemberian penentuan reward. Gambar 4. adalah model PDCA untuk penentuan reward karyawan.

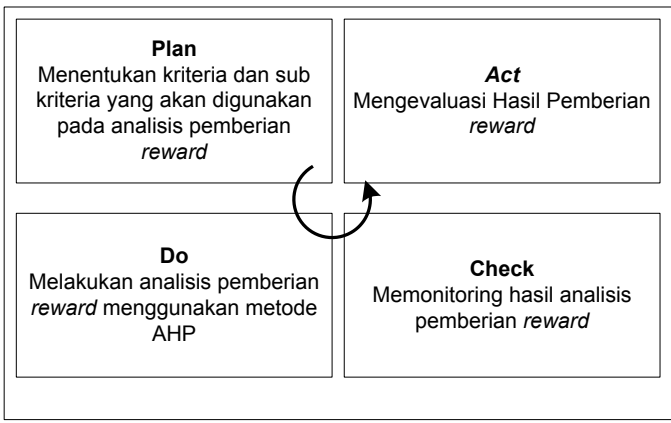

Gambar 4. Model PDCA Pemberian Reward

\section{Perancanaan (Plan) Pemberian Reward}

Tahapan Perencanaan Analisis Pemberian Reward Karyawan yaitu :

a. Membuat Struktur Hierarki Pemberian Reward

Struktur Hierarki Pemberian reward terlihat pada Gambar 5.

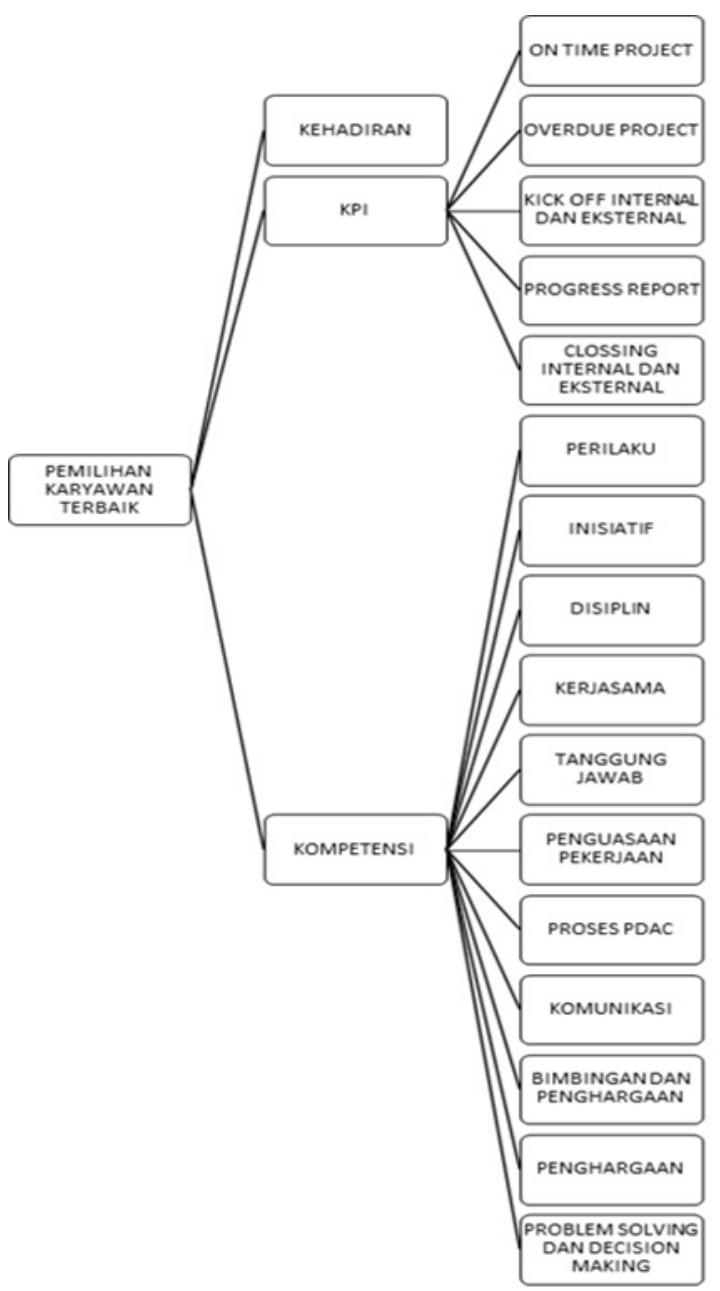

Gambar 5. Struktur Hierarki AHP Pemberian Reward

b. Menentukan kriteria dan sub kriteria

Kriteria yang dimiliki perusahaan terdapat pada Tabel 1.

Tabel 1. Kriteria Pemberian Reward

\begin{tabular}{|l|l|}
\hline \multicolumn{2}{|c|}{ KRITERIA } \\
\hline A & Kehadiran \\
\hline B & KPI \\
\hline C & Kompetensi \\
\hline
\end{tabular}


Pada metode AHP akan dilakukan pembobotan untuk dimensi diatas dengan aturan yang dapat dilihat pada tabel 2.

Tabel 2. Nilai Tingkat Kepentingan pada metode AHP

\begin{tabular}{|c|c|}
\hline Nilai & Keterangan \\
\hline 1 & $\begin{array}{l}\text { Jika kriteria } 1 \text { sama penting dengan kriteria } \\
2\end{array}$ \\
\hline 3 & $\begin{array}{l}\text { Jika kriteria } 1 \text { sedikit lebih penting dari } \\
\text { krteria } 2\end{array}$ \\
\hline 5 & Jika kriteria 1 lebih penting dari kriteria 2 \\
\hline 7 & $\begin{array}{l}\text { Jika kriteria } 1 \text { lebih mutlak penting dari } \\
\text { kriteria } 2\end{array}$ \\
\hline 9 & $\begin{array}{l}\text { Jika kriteria } 1 \text { mutlak lebih penting dari } \\
\text { kriteria } 1\end{array}$ \\
\hline $\begin{array}{l}2,4,6 \\
8\end{array}$ & Jika nilainya mendekati antara 2 nilai \\
\hline
\end{tabular}

Berdasarkan aturan tersebut maka diperoleh hasil seperti pada tabel 3.

Tabel 3. Hasil Pembobotan pada Kriteria Pemberian Reward

\begin{tabular}{|l|r|r|r|}
\hline Kriteria & KEHADIRAN & \multicolumn{1}{c|}{ KPI } & KOMPETENSI \\
\hline KEHADIRAN & 1.00 & 0.1 & 4 \\
\hline KPI & 7.00 & 0 & 0.33 \\
\hline KOMPETENSI & 3.00 & 3 & 2.33 \\
\hline TOTAL & 11.00 & 1.5 & 1.00 \\
\hline
\end{tabular}

Lalu lakukan normalisasi pada matriks diatas dengan cara membagi nilai setiap field dengan total pada setiap kolom sehingga didapatkan matriks yang telah normal pada tabel 4 .

Tabel 4. Hasil Normalisasi Matriks Pembobotan Pemberian Reward

\begin{tabular}{|l|r|r|r|r|r|}
\hline \multicolumn{1}{|c|}{ Kriteria } & $\begin{array}{c}\text { KE } \\
\text { HADIRAN }\end{array}$ & KPI & $\begin{array}{c}\text { KOM } \\
\text { PETENSI }\end{array}$ & $\begin{array}{c}\text { Priority } \\
\text { vector }\end{array}$ \\
\hline $\begin{array}{l}\text { KEHADIR } \\
\text { AN }\end{array}$ & 0.09 & $\begin{array}{r}0.0 \\
9\end{array}$ & 0.09 & $\begin{array}{r}0.2 \\
7\end{array}$ & 0.09 \\
\hline KPI & 0.64 & $\begin{array}{r}0.6 \\
\text { KOMPET }\end{array}$ & 0.64 & $\begin{array}{r}1.9 \\
1\end{array}$ & 0.64 \\
\hline $\begin{array}{l}\text { ENSI } \\
\text { TOTAL }\end{array}$ & 0.27 & $\begin{array}{r}0.2 \\
7\end{array}$ & 0.27 & $\begin{array}{r}0.8 \\
2\end{array}$ & 0.27 \\
\hline
\end{tabular}

Hitung priority vector dengan cara menormalisasikan nilai jumlah pada setiap baris hasil normalisasi. Setelah itu, uji konsistensi dari nilai diatas dengan cara mengalikan matriks awal dengan priority vector lalu membaginya dengan nilai priority vector. Didapatkan hasil seperti pada tabel 5.

Tabel 5. Uji Konsistensi matriks AHP

\begin{tabular}{|r|r|r|r|r|r|}
\hline \multicolumn{3}{|c|}{ kriteria } & $\begin{array}{c}\text { Priority } \\
\text { vector }\end{array}$ & $\begin{array}{c}\text { hasil } \\
\text { hasil } \\
\text { kali }\end{array}$ & $\begin{array}{c}\text { kali/ } \\
\text { priority } \\
\text { vector }\end{array}$ \\
\hline 1.00 & 0.14 & 0.33 & 0.09 & 0.27 & 3 \\
\hline 7.00 & 1.00 & 2.33 & 0.64 & 1.91 & 3 \\
\hline 3.00 & 0.43 & 1.00 & 0.27 & 0.82 & 3 \\
\hline
\end{tabular}

Tahap selanjutnya yaitu menghitung total weight untuk setiap dimensi yang terlihat pada Tabel 6 .

Tabel 6. Nilai Local Weight Untuk Setiap Dimensi

\begin{tabular}{|l|l|l|}
\hline \multicolumn{2}{|c|}{ DIMENSI } & LOCAL WEIGHTS \\
\hline A & Kehadiran & 0.09 \\
\hline B & KPI & 0.64 \\
\hline C & kompetensi & 0.27 \\
\hline
\end{tabular}

\section{- Kehadiran}

Pada dimensi kehadiran, tidak memiliki sub indicator. Penilaian kehadiran dilakukan dengan cara seperti pada tabel 7 .

Tabel 7. Perhitungan Kehadiran

\begin{tabular}{|l|l|l|c|c|}
\hline \multicolumn{1}{|c|}{ Absensi } & Jml & Satuan & Point & $\begin{array}{c}\text { Total } \\
\text { Point }\end{array}$ \\
\hline $\begin{array}{l}\text { Jumlah } \\
\text { Kehadiran }\end{array}$ & & Hari & 2 & 0 \\
\hline $\begin{array}{l}\text { Sakit tanpa } \\
\text { ket. Dokter }\end{array}$ & & Kali & -1 & 0 \\
\hline $\begin{array}{l}\text { Alpha/ } \\
\text { Mangkir }\end{array}$ & Kali & -3 & 0 \\
\hline Tidak Absen & & Kali & -3 & 0 \\
\hline Sub Total & & & & 0 \\
\hline ljin jam kerja & & Kali & -0.5 & 0 \\
\hline Terlambat & & Kali & -1.5 & 0 \\
\hline $\begin{array}{l}\text { Total point } \\
\text { kehadiran }(x)\end{array}$ & & & & 0 \\
\hline $\begin{array}{l}\text { Jumlah total } \\
\text { hari kerja 1 } \\
\text { periode (y) }\end{array}$ & & Hari & 2 & 0 \\
\hline $\begin{array}{l}\text { Persentase } \\
\text { kehadiran }(x) \\
\text { y)*100 }\end{array}$ & & & & \\
\hline
\end{tabular}




\section{- KPI ( Key Performance Indicator )}

Pada dimensi KPI memiliki sub indikator, dengan cara yang sama seperti pada perhitungan pada pembobotan dimensi, didapatkan hasil local weights seperti pada tabel 8 .

Tabel 8. Hasil Analisis Pembobotan pada Subkriteria $\mathrm{KPI}$

\begin{tabular}{|l|l|l|}
\hline \multicolumn{2}{|c|}{ Sub indicator } & Local weights \\
\hline B1 & On Time Project & 0.60 \\
\hline B2 & Overdue Project & 0.20 \\
\hline B3 & $\begin{array}{l}\text { Kickoff internal dan } \\
\text { eksternal }\end{array}$ & 0.08 \\
\hline B4 & $\begin{array}{l}\text { Progress report proyek } \\
\text { untuk internal/external PMO }\end{array}$ & 0.05 \\
\hline B5 & $\begin{array}{l}\text { Closing internal dan } \\
\text { eksternal }\end{array}$ & 0.08 \\
\hline
\end{tabular}

\section{- Kompetensi}

Dan untuk sub indikator kompetensi dengan cara yang sama didapatkan hasil seperti pada tabel 9 .

Tabel 9. Hasil Analisis Pembobotan pada Subindikator Kompetensi

\begin{tabular}{|l|l|l|}
\hline \multicolumn{2}{|c|}{ Sub indikator } & $\begin{array}{c}\text { Local } \\
\text { weights }\end{array}$ \\
\hline C1 & Perilaku & 0.10 \\
\hline C2 & Inisiatif & 0.10 \\
\hline C3 & Disiplin & 0.10 \\
\hline C4 & Kerjasama & 0.10 \\
\hline C5 & Tanggung jawab & 0.10 \\
\hline C6 & Penguasaan pekerjaan & 0.10 \\
\hline C7 & Proses PDAC & 0.10 \\
\hline C8 & Komunikasi & 0.10 \\
\hline C9 & Bimbingan dan penghargaan & 0.03 \\
\hline C10 & Penghargaan & 0.03 \\
\hline C11 & $\begin{array}{l}\text { Problem solving \& decision } \\
\text { making }\end{array}$ & 0.10 \\
\hline
\end{tabular}

c. Menghitung global weight

Nilai global weight didapatkan dengan cara mengalikan nilai bobot pada setiap dimensi dengan nilai local weight pada sub indikator. Tabel 10 adalah hasil perhitungan untuk global weight.

Tabel 10. Hasil Perhitungan Global Weight

\begin{tabular}{|c|c|c|c|c|c|c|}
\hline \multicolumn{3}{|c|}{ Kriteria } & \multicolumn{3}{|c|}{ Indikator } & \multirow[b]{2}{*}{$\begin{array}{c}\text { Glob- } \\
\text { al } \\
\text { Weig } \\
\text { hts }\end{array}$} \\
\hline NO & & $\begin{array}{c}\text { Loc } \\
\text { al } \\
\text { weig } \\
\text { hts }\end{array}$ & NO & & $\begin{array}{c}\text { Local } \\
\text { weig } \\
\text { hts }\end{array}$ & \\
\hline A & $\begin{array}{c}\text { Kehadi } \\
\text { ran }\end{array}$ & 0.09 & & & & 0.09 \\
\hline \multirow{5}{*}{ B } & \multirow{5}{*}{ KPI } & \multirow{5}{*}{0.64} & B1 & $\begin{array}{l}\text { On } \\
\text { Time } \\
\text { Project }\end{array}$ & 0.60 & $\begin{array}{c}0.38 \\
4\end{array}$ \\
\hline & & & B2 & $\begin{array}{l}\text { Overd } \\
\text { ue } \\
\text { Project }\end{array}$ & 0.20 & $\begin{array}{c}0.12 \\
8\end{array}$ \\
\hline & & & B3 & $\begin{array}{l}\text { Kickoff } \\
\text { intern } \\
\text { al dan } \\
\text { ekster } \\
\text { nal }\end{array}$ & 0.08 & $\begin{array}{c}0.05 \\
12\end{array}$ \\
\hline & & & B4 & $\begin{array}{l}\text { Progre } \\
\text { ss } \\
\text { report } \\
\text { proyek } \\
\text { untuk } \\
\text { intern } \\
\text { al/ } \\
\text { extern } \\
\text { al } \\
\text { PMO }\end{array}$ & 0.05 & $\begin{array}{c}0.03 \\
2\end{array}$ \\
\hline & & & B5 & $\begin{array}{l}\text { Closin } \\
\text { g } \\
\text { intern } \\
\text { al dan } \\
\text { ekster } \\
\text { nal }\end{array}$ & 0.08 & $\begin{array}{c}0.05 \\
12\end{array}$ \\
\hline
\end{tabular}




\begin{tabular}{|c|c|c|c|c|c|c|}
\hline \multicolumn{3}{|c|}{ Kriteria } & \multicolumn{3}{|c|}{ Indikator } & \multirow[b]{2}{*}{$\begin{array}{c}\text { Glob- } \\
\text { al } \\
\text { Weig } \\
\text { hts }\end{array}$} \\
\hline NO & & $\begin{array}{c}\text { Loc } \\
\text { al } \\
\text { weig } \\
\text { hts }\end{array}$ & NO & & $\begin{array}{c}\text { Local } \\
\text { weig } \\
\text { hts }\end{array}$ & \\
\hline \multirow{11}{*}{ C } & \multirow{11}{*}{$\begin{array}{l}\text { Komp } \\
\text { etensi }\end{array}$} & \multirow{11}{*}{0.27} & C1 & $\begin{array}{l}\text { Perila } \\
\text { ku }\end{array}$ & 0.10 & $\begin{array}{c}0.02 \\
7\end{array}$ \\
\hline & & & $\mathrm{C} 2$ & $\begin{array}{l}\text { Inisiati } \\
\mathrm{f}\end{array}$ & 0.10 & $\begin{array}{c}0.02 \\
7\end{array}$ \\
\hline & & & C3 & $\begin{array}{l}\text { Disipli } \\
n\end{array}$ & 0.10 & $\begin{array}{c}0.02 \\
7\end{array}$ \\
\hline & & & C4 & $\begin{array}{l}\text { Kerjas } \\
\text { ama }\end{array}$ & 0.10 & $\begin{array}{c}0.02 \\
7\end{array}$ \\
\hline & & & C5 & $\begin{array}{l}\text { Tangg } \\
\text { ung } \\
\text { jawab }\end{array}$ & 0.10 & $\begin{array}{c}0.02 \\
7\end{array}$ \\
\hline & & & C6 & $\begin{array}{l}\text { Pengu } \\
\text { asaan } \\
\text { pekerj } \\
\text { aan }\end{array}$ & 0.10 & $\begin{array}{c}0.02 \\
7\end{array}$ \\
\hline & & & C7 & $\begin{array}{l}\text { Prose } \\
\mathrm{S} \\
\text { PDAC }\end{array}$ & 0.10 & $\begin{array}{c}0.02 \\
7\end{array}$ \\
\hline & & & C8 & $\begin{array}{l}\text { Komu } \\
\text { nikasi }\end{array}$ & 0.10 & $\begin{array}{c}0.02 \\
7\end{array}$ \\
\hline & & & C9 & $\begin{array}{l}\text { Bimbi } \\
\text { ngan } \\
\text { dan } \\
\text { pengh } \\
\text { argaa } \\
\text { n }\end{array}$ & 0.03 & $\begin{array}{c}0.08 \\
1\end{array}$ \\
\hline & & & $\begin{array}{c}\mathrm{C} 1 \\
0\end{array}$ & $\begin{array}{l}\text { Pengh } \\
\text { argaa } \\
\text { n }\end{array}$ & 0.03 & $\begin{array}{c}0.08 \\
1\end{array}$ \\
\hline & & & $\begin{array}{c}\mathrm{C} 1 \\
1\end{array}$ & $\begin{array}{l}\text { Proble } \\
\mathrm{m} \\
\text { solvin } \\
\mathrm{g} \& \\
\text { decisi } \\
\text { on } \\
\text { makin } \\
\mathrm{g}\end{array}$ & 0.10 & $\begin{array}{c}0.02 \\
7\end{array}$ \\
\hline
\end{tabular}

Hasil dari Tabel 10 merupakan hasil pembobotan menggunakan AHP dan akan digunakan untuk tahapn Pelaksanaan (Do).

\section{- Pelaksanaan (Do) Pemberian Reward}

Pada tahap pelaksanaan dilakukan penilaian berdasarkan nilai yang telah ditentukan pada tahap plan untuk setiap karyawan di perusahaan. Sebagai contoh karyawan dengan nama Aditya Eka Pramana dengan jabatan Project Manager. Penilaian Kehadiran dari karyawan tersebut terdapat di Tabel 11.

Tabel 11. Hasil Perhitungan Karyawan

\begin{tabular}{|l|c|c|c|c|}
\hline \multicolumn{1}{|c|}{ Absensi } & Jml & Satuan & Point & $\begin{array}{c}\text { Total } \\
\text { Point }\end{array}$ \\
\hline $\begin{array}{l}\text { Jumlah } \\
\text { Kehadiran }\end{array}$ & 230 & Hari & 2 & 460 \\
\hline $\begin{array}{l}\text { Sakit tanpa } \\
\text { ket. Dokter }\end{array}$ & 0 & Kali & -1 & 0 \\
\hline $\begin{array}{l}\text { Alpha/ } \\
\text { Mangkir }\end{array}$ & 0 & Kali & -3 & 0 \\
\hline Tidak Absen & 2 & Kali & -3 & -6 \\
\hline Sub Total & 2 & Kali & -0.5 & -1 \\
\hline ljin jam kerja & 3 & Kali & -1.5 & -4.5 \\
\hline Terlambat & & Hari & 2 & 448.5 \\
\hline $\begin{array}{l}\text { Total point } \\
\text { kehadiran (x) }\end{array}$ & & & & \\
\hline $\begin{array}{l}\text { Jumlah total } \\
\text { hari kerja 1 } \\
\text { periode (y) }\end{array}$ & 245 & & & \\
\hline $\begin{array}{l}\text { Persentase } \\
\text { kehadiran (x / } \\
\text { y)*100 }\end{array}$ & & & & \\
\hline
\end{tabular}

Nilai yang dihasilkan pada tabel diatas dapat kita langsung masukan kedalam tabel penilaian yang telah ditentukan pada tahan Plan . sehingga kita dapatkan tabel 12 hasil penilaian untuk karyawan dengan nama Aditya Eka Pramana. 
Tabel 12. Hasil Perhitungan Penilaian Karyawan

\begin{tabular}{|c|c|c|c|c|c|c|}
\hline & \multicolumn{2}{|c|}{ Kriteria } & \multicolumn{2}{|l|}{ Nilai } & $\begin{array}{c}\text { Glob } \\
\text { al } \\
\text { weig } \\
\text { ht } \\
\text { s }\end{array}$ & $\begin{array}{c}\text { Nilai * } \\
\text { Global } \\
\text { Weight } \\
\text { s }\end{array}$ \\
\hline A & $\begin{array}{c}\text { Ke } \\
\text { hadir } \\
\text { an }\end{array}$ & & & 92 & 0.09 & 8.2 \\
\hline \multirow{5}{*}{ B } & \multirow{5}{*}{$\mathrm{KPI}$} & B1 & $\begin{array}{c}\text { On Time } \\
\text { Project }\end{array}$ & 90 & 0.38 & 34.5 \\
\hline & & B2 & $\begin{array}{c}\text { Overdue } \\
\text { Project }\end{array}$ & 85 & 0.13 & 10.8 \\
\hline & & B3 & $\begin{array}{c}\text { Kickoff } \\
\text { internal } \\
\text { dan } \\
\text { eksternal }\end{array}$ & 85 & 0.05 & 4.3 \\
\hline & & B4 & $\begin{array}{l}\text { Progress } \\
\text { report } \\
\text { proyek } \\
\text { untuk } \\
\text { internal/ } \\
\text { external } \\
\text { PMO }\end{array}$ & 90 & 0.32 & 28.8 \\
\hline & & B5 & $\begin{array}{l}\text { Closing } \\
\text { internal } \\
\text { dan } \\
\text { eksternal }\end{array}$ & 90 & 0.05 & 4.6 \\
\hline \multirow{11}{*}{ C } & \multirow{11}{*}{$\begin{array}{c}\text { Kom } \\
\text { pete } \\
\text { nsi }\end{array}$} & $\mathrm{C} 1$ & Perilaku & 90 & 0.03 & 2.4 \\
\hline & & $\mathrm{C} 2$ & Inisiatif & 90 & 0.03 & 2.4 \\
\hline & & C3 & Disiplin & 80 & 0.03 & 2.1 \\
\hline & & $\mathrm{C4}$ & Kerjasama & 90 & 0.03 & 2.4 \\
\hline & & C5 & $\begin{array}{c}\text { Tanggung } \\
\text { jawab }\end{array}$ & 90 & 0.03 & 2.4 \\
\hline & & C6 & $\begin{array}{c}\text { Penguasa } \\
\text { an } \\
\text { pekerjaan }\end{array}$ & 90 & 0.03 & 2.4 \\
\hline & & $\mathrm{C} 7$ & $\begin{array}{c}\text { Proses } \\
\text { PDAC }\end{array}$ & 90 & 0.03 & 2.4 \\
\hline & & $\mathrm{C} 8$ & $\begin{array}{c}\text { Komunika } \\
\text { si }\end{array}$ & 85 & 0.03 & 2.2 \\
\hline & & $\mathrm{Cg}$ & $\begin{array}{c}\text { Bimbingan } \\
\text { dan } \\
\text { pengharga } \\
\text { an }\end{array}$ & 85 & 0.08 & 6.8 \\
\hline & & $\begin{array}{c}C \\
10 \\
\end{array}$ & $\begin{array}{c}\text { Pengharga } \\
\text { an } \\
\end{array}$ & 85 & 0.08 & 6.8 \\
\hline & & $\begin{array}{c}C \\
11\end{array}$ & $\begin{array}{c}\text { Problem } \\
\text { solving \& } \\
\text { decision } \\
\text { making }\end{array}$ & 90 & 0.03 & 2.4 \\
\hline & & & & & TOTAL & 126.7 \\
\hline
\end{tabular}

Dari tabel diatas menyatakan bahwa karyawan Aditya Eka Pramana mendapatkan nilai 126,7 . dan lakukan hal yang sama untuk semua karyawan yang ada di PT.SWAMEDIA INFORMATIKA.

\section{- Pengendalian (Check) Pemberian Reward}

Hasil pada tahap pelaksanaan, dilakukan penilaian dengan cara yang sama untuk semua karyawan. Juga pengeliminasian untuk karyawan yang memiliki surat peringatan. sehingga didapatkan nilai lima teratas seperti pada tabel 13.

Tabel 13. Data Karyawan Calon Penerima Reward

\begin{tabular}{|l|l|l|}
\hline No & \multicolumn{1}{|c|}{ Nama } & \multicolumn{1}{|c|}{ Nilai } \\
\hline 1 & Aditya Eka Pramana & 126.715 \\
\hline 2 & Arfi Finandhita & 121.111 \\
\hline 3 & Deded & 128.29 \\
\hline 4 & Decki permana & 125.87 \\
\hline 5 & Rangga Gumilar & 126.26 \\
\hline
\end{tabular}

Kelima kandidat diatas merupakan karyawan dengan nilai tertinggi dari semua karyawan. Data diatas selanjutnya akan dianalis pada tahap pengevaluasian. Jika karyawan mendapatkan nilai tertinggi maka Karyawan tersebut akan mendapatkan reward berupa Umroh.

\section{- Pengevaluasian (Act) Pemberian Reward}

Berdasarkan hasil pelaksanaan penilaian karyawan yang berhak mendapatkan reward, diketahui bahwa Karyawan yang bernama Deded memiliki Nilai tertinggi yaitu 128,29. Karyawan tersebut berhak mendapatkan reward berupa perjalanan Umroh bersama 2 orang anggota keluarganya.

\section{KESIMPULAN}

Berdasarkan hasil analisis yang telah dilakukan sebelumnya, maka dapat ditarik kesimpulan bahwa pemberian reward menggunakan metode AHP dapat mempermudah perusahaan dalam menentukan karyawan yang pantas dan layak mendapatkan reward berdasarkan nilai dan bobot yang telah ditentukan sebelumnya. Hal ini dapat dijadikan sebagai acuan perusahaan dalam memberikan reward. 


\section{DAFTAR PUSTAKA}

[1] T. Harihayati, U.D Widianti, "Model Sistem Informasi Manajemen Kepegawaian di PT. XYZ", 2017, SEMNASTEKNOMEDIA ONLINE, 5(1), 12

[2] M. A. Anshari, "Pembangunan Sistem Informasi Monitoring dan Evaluasi Kinerja Karyawan di Baraya Travel", 2014, Skripsi, Program Studi Teknik Informatika, UNIKOM

[3] K. Ludfiandini, S. Nugroho, " Analisis dan Penilaian Kinerja Karyawan pada Operator Dump Truck Perusahaan Pertambangan Menggunakan Metode AHP dan Rating Scale (Studi Kasus pada PT. Pama Indo Mining", 2013, Skripsi, Program Studi Teknik Industri, Universitas Diponegoro

[4] H. Nawawi, "Manajemen Sumber Daya Manusia”, 2001, Bumi Aksara, Jakarta

[5] V. Rivai, “Manajemen Sumber Daya Manusia untuk Perusahaan”, 2003, Rajagrafindo Persada, Jakarta
[6] A. Dewi, H. Nugraha, S. Listyorini, "ANALISIS PENGENDALIAN KUALITAS DENGAN PENDEKATAN P.D.C.A. (PLAN-DO-CHECK-ACT) BERDASARKAN STANDAR MINIMAL PELAYANAN RUMAH SAKIT PADA RSUD DR. ADHYATMA SEMARANG (STUDI KASUS PADA INSTALASI RADIOLOGI)," 2013, Jurnal Ilmu Administrasi Bisnis, vol. [Online]

[7] R. Susanto, A.D Andriana. "ANALISIS METODE 360 DERAJAT UNTUK PENILAIAN KINERJA KARYAWAN PADA SISTEM INFORMASI MANAJEMEN SUMBER DAYA MANUSIA", 2019, Majalah IImiah Unikom.

[8] Susanto, R. (2018, August). "Raw material inventory control analysis with economic order quantity method". In IOP Conference Series: Materials Science and Engineering (Vol. 407, No. 1, p. 012070). IOP Publishing. 
$\begin{array}{lll}\text { Majalah IImiah UNIKOM } & \text { Vol.17 No. } 2\end{array}$

\section{\begin{tabular}{l|l} 
Halaman & 152
\end{tabular}}

